\title{
Pharmacology, efficacy and safety of liraglutide in the management of type 2 diabetes
}

This article was published in the following Dove Press journal:

Diabetes, Metabolic Syndrome and Obesity:Targets and Therapy 10 July 2010

Number of times this article has been viewed

\section{Joshua J Neumiller' \\ Travis E Sonnett ${ }^{2}$ \\ Lindy D Wood' \\ Stephen M Setter' \\ R Keith Campbell ${ }^{2}$}

'Department of Pharmacotherapy, College of Pharmacy, Washington State University, Spokane, Washington;

${ }^{2}$ Department of Pharmacotherapy, College of Pharmacy, Washington State University, Pullman, Washington, USA
Correspondence: Joshua J Neumiller Department of Pharmacotherapy, College of Pharmacy, Washington State University, PO Box 1495, Spokane, WA 99210 - I495, USA

Tel +I 5094587450

Fax +I 5094587459

Email jneumiller@wsu.edu

\begin{abstract}
Liraglutide is a glucagon-like peptide-1 analog with pharmacokinetic properties suitable for once-daily administration approved by the Food and Drug Administration for the treatment of patients with type 2 diabetes. Clinical trial data from large, controlled studies demonstrate the safety and efficacy of liraglutide in terms of hemoglobin $\mathrm{A}_{1 \mathrm{c}}\left(\mathrm{HbA}_{1 \mathrm{c}}\right)$ reduction, reductions in body weight, and the drug's low risk for hypoglycemic events when used as monotherapy. Liraglutide has been studied as monotherapy and in combination with metformin, glimepiride, and rosiglitazone for the treatment of type 2 diabetes. Additionally, comparative data with insulin glargine and exenatide therapy are available from Phase III trials. Once-daily administration may provide a therapeutic advantage for liraglutide over twice-daily exenatide, with similar improvements in $\mathrm{HbA}_{1 \mathrm{c}}$ and body weight observed when liraglutide was compared with exenatide. The glucose-dependent mechanism of insulin release with incretin analog therapy holds potential clinical significance in the management of postprandial hyperglycemic excursions, with minimal risk of hypoglycemia when used with non-secretagogue medications. Data to date on patient-reported outcomes with liraglutide treatment are encouraging. The most common adverse events associated with liraglutide therapy are dose-dependent nausea, vomiting, and diarrhea. Diligent postmarketing surveillance to elucidate the risk of pancreatitis and medullary thyroid carcinoma in a heterogeneous population are likely warranted.
\end{abstract}

Keywords: incretin analog, incretin effect, liraglutide, diabetes

\section{Introduction}

The burden of diabetes continues to grow, both globally to more than 220 million people worldwide with diabetes ${ }^{1}$ and in the US, where more than 23.6 million people have the disease. ${ }^{2}$ Although numerous interventions and medications exist to treat diabetes, less than half of adults in the US with diabetes are able to reach the target glycosylated hemoglobin $\mathrm{A}_{1 \mathrm{c}}\left(\mathrm{HbA}_{1 \mathrm{c}}\right)$ level, as set by the American Diabetes Association (ADA), of less than $7 \%$ for most patients. ${ }^{3,4}$ Attaining and maintaining glycemic control in type 2 diabetes mellitus (T2DM) is complicated by disease progression and continued $\beta$-cell deterioration. ${ }^{5}$ Benefits of intensive glucose control include a reduction in microvascular complications, as well as the so-called "legacy effect". This effect refers to the results of a 10-year follow-up study to the United Kingdom Prospective Diabetes Study, which found that intensive glucose control in newly diagnosed T2DM patients provided longterm benefits on cardiovascular outcomes and mortality, even if intensive control was not sustained in the long term. ${ }^{6}$ Considering these findings, and that $18 \%$ of patients developed a diabetes-related complication within 6 years of diagnosis in the United 
Kingdom Prospective Diabetes Study, ${ }^{7}$ it is clear that glycemic control starting at the time of T2DM diagnosis is important.

While lifestyle modifications, including diet and exercise, were once the initial treatment for patients with T2DM, it is now recognized that these interventions are insufficient for most patients, and pharmacotherapy should not be delayed. ${ }^{8}$ Thus, the initial management of a patient presenting with T2DM consists of both lifestyle modification and medication, most specifically metformin, as recommended by the ADA. ${ }^{9}$ While monotherapy may suffice in the short term, most patients will need polypharmacy to achieve and sustain glycemic control. ${ }^{5}$ The ADA recommends initial combination therapy in newly diagnosed patients with an $\mathrm{HbA}_{1 \mathrm{c}}$ of $>8.5 \%$, ${ }^{9}$ while a consensus panel for the American Association of Clinical Endocrinologists (AACE) and the American College of Endocrinology (ACE) is even more aggressive, recommending dual therapy for patients with an $\mathrm{HbA}_{1 \mathrm{c}}$ between $7.6 \%$ and $9 \%$, and triple therapy or insulin for those with an initial $\mathrm{HbA}_{1 \mathrm{c}}$ of $>9 \%{ }^{8}$

Because the choice of initial therapy and adjunctive therapy for intensification is increasingly individualized to the patient, agents that were once viewed solely as add-on therapy are now being considered much earlier in the course of treatment. Glucagon-like peptide-1 (GLP-1) agonists and dipeptidyl peptidase-4 (DPP-4) inhibitors are examples of such agents. The AACE/ACE diabetes algorithm recommends monotherapy for patients with an initial $\mathrm{HbA}_{1 \mathrm{c}}$ of $6.5 \%-7.5 \%{ }^{8}$ While metformin is the preferred initial agent, GLP-1 receptor agonists, DPP-4 inhibitors, thiazolidinediones, and alpha-glucosidase inhibitors are included as alternatives. ${ }^{8}$ For patients requiring dual or triple therapy, the AACE/ACE preferentially recommends the addition of a GLP-1 agonist or a DPP-4 inhibitor, citing their efficacy and safety profiles, over thiazolidinediones or sulfonylureas. ${ }^{8}$ Following initial treatment with metformin, the ADA, in contrast, recommends intensification with either basal insulin or a sulfonylurea (both Tier 1, or well validated therapies), pioglitazone or a GLP-1 agonist (both Tier 2, or less well validated therapies). ${ }^{9}$ Not only have such treatment algorithms changed in recent years to recommend GLP-1 agonists earlier, but package labeling is also changing to expand their use. Exenatide, the GLP-1 agonist approved by the Food and Drug Administration (FDA) in 2005 for combination therapy, received an indication for monotherapy in 2009. ${ }^{10}$

This relatively new class of GLP-1 agonists has gained increasing use for a variety of reasons. Agents which mimic the incretin system, such as GLP-1 agonists, have a low incidence of hypoglycemia, often cause weight loss, and may preserve $\beta$-cells or even stimulate their proliferation. ${ }^{11,12}$ In addition to the approval of exenatide, liraglutide was approved by the FDA in January $2010 .{ }^{13}$ This paper will provide an overview of liraglutide and attempt to compare this new incretin analog with exenatide in terms of efficacy, safety, and utility in the treatment of patients with T2DM.

\section{Methods}

A MEDLINE search (1966 - February 2010) was conducted with the key words "liraglutide" and "incretin therapies" for clinical trials and pertinent review articles published in English. References of identified articles were searched for additional relevant sources. Abstracts from the ADA and European Association for the Study of Diabetes annual meetings presented in 2006, 2007, 2008, and 2009 were also searched for relevant data. English language articles pertinent to the pharmacology, pharmacokinetics, efficacy, safety, and patient-related outcomes of liraglutide treatment were reviewed. Six Phase III clinical trials from the Liraglutide Effects and Action in Diabetes (LEAD) program have been published. Reports on patient-reported outcomes and quality of life measures have also been published and are discussed herein.

\section{Pharmacology}

A role for an intestinal mediator of insulin secretion was initially conceived by the observation that the oral intake of glucose resulted in a greater insulin response when compared with intravenous glucose administration..$^{14,15}$ This "incretin effect" is now known to be due to the stimulation of insulin release by the oral intake of nutrients which results in insulin secretion above and beyond the insulin release induced by increased blood glucose concentrations alone. The incretin effect is now recognized as being responsible for approximately $60 \%$ of the insulin response to a given meal. ${ }^{16}$ Of clinical significance, the incretin effect has been shown to be greatly impaired in patients with T2DM. ${ }^{17}$ The incretin effect is primarily attributed to 2 insulinotropic gut hormones, ie, GLP-1 and glucose-dependent insulinotropic polypeptide (GIP). GLP-1 is a 30 -amino acid peptide released from L-cells of the intestine in response to a meal, ${ }^{18}$ and GIP is released by duodenal cells of the proximal small bowel. ${ }^{19}$ GLP-1 secretion is known to be deficient in patients with T2DM, ${ }^{20,21}$ and GLP-1 infusion has been shown experimentally to lower glucose levels via enhanced glucose-dependent insulin secretion in subjects with T2DM. ${ }^{22-24}$ Further study with GLP-1 in subjects with T2DM has demonstrated beneficial effects of GLP-1 on decreasing inappropriate 
glucagon secretion, ${ }^{25,26}$ slowing of gastric emptying, ${ }^{27,28}$ and increased satiety and decreased food intake. ${ }^{29}$

While GLP-1 has demonstrated clinical utility in the management of patients with T2DM, endogenous GLP-1 is rapidly degraded by the enzyme DPP-4, resulting in a GLP-1 half-life of approximately 1-2 minutes. ${ }^{30}$ The development of DPP-4 resistant GLP-1 analogs has been one strategy by which to utilize the beneficial effects of GLP-1 in patients with T2DM. Liraglutide is the newest incretin analog currently available in the US, which is approved for once-daily administration. ${ }^{13}$ In vitro studies indicate that liraglutide retains affinity for GLP-1 receptors despite these structural modifications. ${ }^{31}$ The addition of the $\mathrm{C} 16$ acyl chain allows for noncovalent binding to albumin, both hindering DPP-4 access to the molecule and contributing to a prolonged half-life and duration of action. ${ }^{32}$

\section{Pharmacokinetics}

The structure of liraglutide makes it kinetically unique when compared with the related compound exenatide; liraglutide incorporates a palmitate side chain at position 26 using a $\gamma$-glutamic acid spacer. ${ }^{33,34}$ This change allows for 99\% albumin binding when compared with natural GLP-1, allowing liraglutide to escape glomerular filtration and extend its duration of action. Liraglutide is detected in the urine and feces as metabolites, and is hepatically metabolized and eliminated via the liver and kidneys.

The pharmacokinetic profile of liraglutide makes it a desirable agent for the treatment of T2DM, given the extended time to maximum plasma concentration $\left(\mathrm{T}_{\max }\right)$ and half-life $\left(t_{1 / 2}\right)$. In an initial study performed by Elbrond et al, 72 healthy male subjects received 8 consecutive subcutaneous doses $\left(1.25-20.0 \mu \mathrm{g} / \mathrm{kg}\right.$ per dose) of liraglutide. ${ }^{35}$ Results from this study reported a $\mathrm{T}_{\max }$ of 9-12 hours after dosing, and a plasma $t_{1 / 2}$ of elimination of 11-15 hours. ${ }^{35}$ In a study of 30 healthy male subjects receiving 5 consecutive subcutaneous doses $(1.25-12.5 \mu \mathrm{g} / \mathrm{kg}$ per dose) of liraglutide, the reported $\mathrm{T}_{\max }$ was 10-14 hours, while the plasma $\mathrm{t}_{1 / 2}$ of elimination was 11-13 hours. ${ }^{34}$ Further kinetic studies were performed utilizing liraglutide in a multi-day fashion with different administration times. One study was performed in 11 subjects with T2DM, administering $10 \mu \mathrm{g} / \mathrm{kg}$ subcutaneously once daily at bedtime for 1 day. ${ }^{36}$ The $\mathrm{T}_{\text {max }}$ was found to be $10-14$ hours, consistent with previous studies, while the plasma $t_{1 / 2}$ was found to be 6-14 hours. A second study was performed with liraglutide, administering $6 \mu \mathrm{g} / \mathrm{kg}$ subcutaneously every morning over a 7-day period in 13 T2DM subjects. ${ }^{37}$ Study results reported a $\mathrm{T}_{\max }$ of 7.1-13.1 hours, and a steady-state plasma $t_{1 / 2}$ of 17.9 hours.
Liraglutide was also examined in clinical trials to determine if normal dosing pharmacokinetics would be impacted in both renally and hepatically impaired subjects. Jacobsen et al performed a study in 30 subjects, comprising 24 with varying degrees of renal impairment and 6 healthy subjects, in which $0.75 \mathrm{mg}$ of liraglutide was administered subcutaneously, with 72-hour follow-up blood sampling. ${ }^{38}$ Results from this study found that liraglutide did not adversely impact serum creatinine in mild-to-severe renal impairment, and was not associated with an increased risk of adverse events in this study population. A meta-analysis was performed examining the Phase III LEAD studies, looking at the impact of liraglutide on serum creatinine levels. ${ }^{39}$ When compared with normal subjects, no significant change in serum creatinine occurred with either $1.2 \mathrm{mg}$ daily or $1.8 \mathrm{mg}$ daily dosing; this is considered to be due to the modification of liraglutide's chemical structure when compared with natural GLP-1. Liraglutide was also evaluated in 24 subjects with mild, moderate, severe, or no hepatic impairment. ${ }^{40}$ Subjects were administered $0.75 \mathrm{mg}$ of liraglutide as a single dose, and were evaluated after a 72-hour period to determine if hepatic impairment influenced liraglutide's kinetic and safety profile. After both renal and hepatic evaluations, it was concluded by the researchers that no hepatic or renal dosing adjustments are necessary with liraglutide.

When compared with exenatide, there are several differences that may be advantageous when considering the use of liraglutide. Exenatide was directly compared with liraglutide in the LEAD-6 trial to determine the efficacy and safety of each agent. ${ }^{41}$ Subjects were administered either $1.8 \mathrm{mg} /$ day of liraglutide (202 subjects) or $10 \mu \mathrm{g}$ twice daily of exenatide (187 subjects) for a period of 26 weeks. It was found that liraglutide maintained steady-state plasma levels 24 hours after administration, while exenatide peaked and returned to baseline plasma levels 10-12 hours following administration. Liraglutide was also found to have minimal impact on renal function due to its chemical structure, while exenatide is primarily eliminated through the kidney, and is not recommended for use in severe renal impairment or end-stage renal disease. ${ }^{1}$

\section{Clinical trials}

The LEAD program comprises 6 randomized, controlled, double-blind Phase III clinical studies in participants with T2DM inadequately controlled with lifestyle and dietary interventions or oral antidiabetic therapies. Table 1 provides a summary of select efficacy endpoints reported from the six LEAD studies discussed individually below. ${ }^{42-47}$ 
Table I Select efficacy outcomes from the Liraglutide Effects and Action in Diabetes (LEAD) trials

\begin{tabular}{|c|c|c|c|c|c|c|c|c|c|}
\hline & \multirow[t]{2}{*}{ Pts } & \multicolumn{2}{|l|}{ Treatment } & \multirow{2}{*}{$\begin{array}{l}\text { Treatment } \\
\text { period } \\
\text { (weeks) }\end{array}$} & \multirow{2}{*}{$\begin{array}{l}\text { HbA } A_{1 c} \\
\text { Change } \\
(\%)\end{array}$} & \multirow{2}{*}{$\begin{array}{l}\text { Achievement } \\
\text { of } \mathrm{HbA}_{\mathrm{IC}}<\mathbf{7 \%} \\
\text { (\%) }\end{array}$} & \multirow{2}{*}{$\begin{array}{l}\text { FPG } \\
\text { change } \\
(\mathrm{mg} / \mathrm{dL})\end{array}$} & \multirow{2}{*}{$\begin{array}{l}\text { PPG } \\
\text { change } \\
(\mathrm{mg} / \mathrm{dL})\end{array}$} & \multirow{2}{*}{$\begin{array}{l}\text { BW } \\
\text { change } \\
\text { (kg) }\end{array}$} \\
\hline & & Background & Intervention & & & & & & \\
\hline \multirow[t]{5}{*}{ LEAD- I $^{42}$} & 1041 & Glim 2-4 mg/day & Lir 0.6 mg/day & 26 & $-0.6^{\mathrm{a}}$ & $24^{a}$ & $-13.0^{\mathrm{a}}$ & $-32.4^{\mathrm{a}}$ & $+0.7^{\mathrm{b}}$ \\
\hline & & & Lir 1.2 mg/day & & $-1.08^{\mathrm{a}, \mathrm{b}}$ & $35^{\mathrm{a}, \mathrm{c}}$ & $-28.3^{\mathrm{a}, \mathrm{e}}$ & $-45.0^{\mathrm{a}, \mathrm{f}}$ & $+0.3^{b}$ \\
\hline & & & Lir 1.8 mg/day & & $-1.13^{\mathrm{a}, \mathrm{b}}$ & $42^{\mathrm{a}, \mathrm{d}}$ & $-28.6^{\mathrm{a}, \mathrm{e}}$ & $-48.6^{\mathrm{a}, \mathrm{g}}$ & $-0.2^{\mathrm{b}}$ \\
\hline & & & Ros 4 mg/day & & $-0.44^{\mathrm{a}}$ & 22 & -15.8 & -32.4 & +2.1 \\
\hline & & & Placebo & & +0.23 & 8 & +18.2 & $-7.2^{f}$ & -0.1 \\
\hline \multirow[t]{5}{*}{ LEAD-2 $2^{43}$} & 1091 & Met I g twice daily & Lir 0.6 mg/day & 26 & $-0.7^{\mathrm{a}}$ & $28.0^{i}$ & $-19.8^{a}$ & -30.6 & $-1.8^{b}$ \\
\hline & & & Lir $1.2 \mathrm{mg} /$ day & & $-1.0^{\mathrm{a}, \mathrm{h}}$ & $35.3^{i}$ & $-28.8^{\mathrm{a}}$ & -41.4 & $-2.6^{\mathrm{b}, \mathrm{k}}$ \\
\hline & & & Lir 1.8 mg/day & & $-1.0^{\mathrm{a}, \mathrm{h}}$ & $42.4^{i}$ & $-30.6^{a}$ & $-46.8^{j}$ & $-2.8^{\mathrm{b}, \mathrm{k}}$ \\
\hline & & & Glim 4 mg/day & & $-1.0^{\mathrm{a}}$ & 36.3 & $-23.4^{\mathrm{a}}$ & $-45.0^{i}$ & +1.0 \\
\hline & & & Placebo & & +0.1 & 10.8 & +7.2 & -10.8 & -1.5 \\
\hline \multirow[t]{4}{*}{ LEAD- $3^{44}$} & 746 & Diet/exercise & Lir 1.2 mg/day & 52 & $-0.84^{\prime}$ & $42.8^{m}$ & $-15.1^{n}$ & -30.8 & $-2.1^{b}$ \\
\hline & & $50 \%$ maximum & Lir 1.8 mg/day & & $-1.14^{b}$ & $50.9^{b}$ & $-25.6^{\mathrm{b}}$ & $-37.4^{\circ}$ & $-2.5^{b}$ \\
\hline & & dose of OAD & Glim 8 mg/day & & -0.51 & 27.8 & -5.2 & -24.5 & +1.1 \\
\hline & & monotherapy & & & & & & & \\
\hline \multirow[t]{3}{*}{ LEAD $-4^{45}$} & 533 & Met I g twice daily & Lir 1.2 mg/day & 26 & $-1.48^{\mathrm{a}}$ & $57.5^{\mathrm{a}}$ & $-40^{\mathrm{a}}$ & -47 & $-1.0^{p}$ \\
\hline & & Ros $8 \mathrm{mg} /$ day & Lir 1.8 mg/day & & $-1.48^{\mathrm{a}}$ & $53.7^{\mathrm{a}}$ & $-44^{\mathrm{a}}$ & $-49 i$ & $-2.0^{p}$ \\
\hline & & & Placebo & & -0.54 & 28.1 & -8 & -14 & +0.6 \\
\hline \multirow[t]{3}{*}{ LEAD- $5^{46}$} & 581 & Met I g twice daily & Lir 1.8 mg/day & 26 & $-1.33^{\mathrm{a}, \mathrm{b}}$ & $53.1^{a, q}$ & $-27.9^{a}$ & $-32.6^{a}$ & $-1.8^{\mathrm{a}, \mathrm{b}}$ \\
\hline & & Glim 4 mg/day & Insulin glargine & & -1.09 & 45.8 & -32.2 & -29.0 & +1.6 \\
\hline & & & Placebo & & -0.24 & 15.5 & +9.5 & -0.5 & -0.4 \\
\hline \multirow[t]{2}{*}{ LEAD-6 61} & 464 & Met & Lir 1.8 mg/day & 26 & $-1.12^{b}$ & $54^{r}$ & $-29.0^{\mathrm{b}}$ & $\mathrm{NR}^{\mathrm{s}}$ & -3.2 \\
\hline & & SU & Exen $10 \mu \mathrm{g}$ bid & & -0.79 & 43 & -10.8 & NR & -2.9 \\
\hline
\end{tabular}

Notes: ${ }^{a} P \leq 0.0001$ versus placebo; ${ }^{b} P<0.0001$ versus comparator; ${ }^{c} P=0.0005$ versus comparator; ${ }^{d} P<0.000$ I versus comparator; ${ }^{e} P<0.01$ versus comparator; ${ }^{\mathrm{f}} P=0.043$ versus comparator; ${ }^{g} P=0.0022$ versus comparator; ${ }^{h}$ noninferior to active comparator; ${ }^{i} P<0.02$ versus placebo; ${ }^{i} P<0.001$ versus placebo; ${ }^{k} P \leq 0.01$ versus placebo; ${ }^{I} P=0.0014$ versus comparator; ${ }^{\mathrm{m} P}=0.0007$ versus comparator; ${ }^{\mathrm{n} P}=0.027$ versus comparator; ${ }^{\circ} P=0.0038$ versus comparator; ${ }^{\mathrm{P}} P<0.05$ versus placebo; ${ }^{\mathrm{a}} P=0.0139$ versus comparator; ${ }^{r} P=0.0015$ versus comparator; ${ }^{s}$ Average reduction reported to be significantly greater for exenatide when compared with liraglutide.

Abbreviations: $\mathrm{HbA}_{1 \mathrm{c}}$, hemoglobin $\mathrm{HbA}_{\mathrm{Ic}}$; BW, body weight; Exen, exenatide; FPG, fasting plasma glucose; Glim, glimepiride; Lir, liraglutide; NR, not reported; OAD, oral antidiabetic drug; PPG, postprandial glucose; Pts, participants randomized; Ros, rosiglitazone; SU, sulfonylurea.

\section{Liraglutide versus rosiglitazone as add-on to baseline glimepiride}

LEAD-1 was a 26-week, randomized, double-dummy trial in 1041 patients with T2DM. The objective of the study was to compare the addition of liraglutide to glimepiride therapy with glimepiride monotherapy or the addition of rosiglitazone to baseline glimepiride. ${ }^{42}$ Participants had a mean baseline $\mathrm{HbA}_{1 \mathrm{c}}$ of $8.4 \%$ and a mean age of 56.1 years. Participants received liraglutide $0.6 \mathrm{mg} /$ day, $1.2 \mathrm{mg} /$ day, or $1.8 \mathrm{mg}$ /day in combination with glimepiride, placebo plus glimepiride (2-4 mg/day), or rosiglitazone $4 \mathrm{mg}$ /day plus glimepiride. Mean $\mathrm{HbA}_{1 \mathrm{c}}$ was reduced by $-1.08 \%$ and $-1.13 \%$ with liraglutide $1.2 \mathrm{mg}$ and $1.8 \mathrm{mg}$, respectively. Participants receiving rosiglitazone experienced a mean $\mathrm{HbA}_{1 \mathrm{c}}$ reduction of $-0.44 \%$, and glimepiride monotherapy resulted in a mean $\mathrm{HbA}_{1 \mathrm{c}}$ increase of $0.23 \%$ $(P<0.0001)$. Of those treated with liraglutide $1.2 \mathrm{mg}$ plus glimepiride, $22 \%$ reached an $\mathrm{HbA}_{1 \mathrm{c}}$ less than $6.5 \%$, with $21 \%$ reaching an $\mathrm{HbA}_{1 \mathrm{c}}$ less than $6.5 \%$ with liraglutide $1.8 \mathrm{mg}$ plus glimepiride. In contrast, $4 \%$ of those on glimepiride monotherapy and $10 \%$ of subjects treated with rosiglitazone plus glimepiride reached an $\mathrm{HbA}_{1 \mathrm{c}}$ below 6.5\% $(P<0.0003)$.

\section{Liraglutide versus glimepiride as add-on to baseline metformin}

LEAD-2 was a randomized, double-blind study that enrolled 1091 participants with T2DM..$^{43}$ Participants had a mean baseline $\mathrm{HbA}_{1 \mathrm{c}}$ of $8.4 \%$. Participants received liraglutide $0.6 \mathrm{mg}, 1.2 \mathrm{mg}$, or $1.8 \mathrm{mg}$ once daily added to metformin 1 $\mathrm{g}$ twice daily, placebo plus metformin, or glimepiride $4 \mathrm{mg}$ / day added to metformin. Mean $\mathrm{HbA}_{1 \mathrm{c}}$ reductions of $-0.7 \%$, $-1.0 \%$, and $-1.0 \%$ were observed with liraglutide $0.6 \mathrm{mg}, 1.2$ $\mathrm{mg}$, and $1.8 \mathrm{mg}$ in combination with metformin, respectively. Those receiving metformin monotherapy experienced a mean $\mathrm{HbA}_{1 \mathrm{c}}$ increase of $0.1 \%$, with a decrease of $-1.0 \%$ seen in those receiving glimepiride plus metformin $(P<0.05$ versus liraglutide plus metformin versus placebo plus metformin). Weight loss was achieved in all participants receiving liraglutide, compared with a $1.0 \mathrm{~kg}$ weight gain observed in those receiving glimepiride $(P<0.0001$ for all liraglutide doses when compared with glimepiride). The percentage of patients achieving an $\mathrm{HbA}_{1 \mathrm{c}}$ less than $6.5 \%$ was $11.3 \%$ in the liraglutide $0.6 \mathrm{mg}$ plus metformin group, $19.8 \%$ in the liraglutide $1.2 \mathrm{mg}$ plus metformin group, and $24.6 \%$ in 
the liraglutide $1.8 \mathrm{mg}$ plus metformin group, compared with $4.2 \%$ of those treated with placebo plus metformin, and $22.2 \%$ of those treated with glimepiride plus metformin $(P<0.02$ for all liraglutide doses when compared with placebo).

\section{Liraglutide versus glimepiride as monotherapy}

The LEAD-3 study enrolled 746 patients with T2DM and a mean baseline $\mathrm{HbA}_{1 \mathrm{c}}$ of $8.2 \% .{ }^{44}$ This Phase III, double-blind, parallel-treatment study involved a head-to-head comparison of monotherapy with $1.2 \mathrm{mg} /$ day or $1.8 \mathrm{mg}$ /day of liraglutide or glimepiride $8 \mathrm{mg}$ /day. Any previous oral antidiabetic drugs (up to half the maximal dose) were discontinued at randomization prior to study drug initiation. At 52 weeks of therapy, mean $\mathrm{HbA}_{1 \mathrm{c}}$ reductions from baseline of $-0.84 \%(P=0.0014$ versus glimepiride $)$ and $-1.4 \%(P<0.0001$ versus glimepiride $)$ were seen with liraglutide $1.2 \mathrm{mg}$ and $1.8 \mathrm{mg}$, compared with a reduction of $-0.51 \%$ for glimepiride. Twenty-seven percent of patients on liraglutide $1.8 \mathrm{mg}$ and $16 \%$ of patients on glimepiride attained an $\mathrm{HbA}_{1 \mathrm{c}}$ less than 6.5\%. Decreases in body weight observed were $-2.1 \mathrm{~kg}$ and $-2.5 \mathrm{~kg}$ for liraglutide $1.2 \mathrm{mg}$ and $1.8 \mathrm{mg}$, respectively $(P=0.0001$ versus glimepiride for both doses). In contrast, participants receiving glimepiride experienced an average weight gain of $1.1 \mathrm{~kg}$.

\section{Liraglutide as add-on to baseline metformin and rosiglitazone}

LEAD-4 was a 26-week, placebo-controlled trial enrolling 533 patients with T2DM and a mean baseline $\mathrm{HbA}_{1 \mathrm{c}}$ of $8.3 \%{ }^{45}$ LEAD-4 assessed the effect of adding liraglutide $1.2 \mathrm{mg}$ or $1.8 \mathrm{mg}$ to baseline metformin $1 \mathrm{~g}$ twice daily plus rosiglitazone $8 \mathrm{mg}$ /day. Liraglutide addition resulted in mean $\mathrm{HbA}_{1 \mathrm{c}}$ reductions of $-1.48 \%$ for both liraglutide doses compared with $-0.54 \%$ observed with the addition of placebo $(P=0.0001)$. An $\mathrm{HbA}_{1 \mathrm{c}}$ less than $6.5 \%$ was achieved in $35 \%$ and $37 \%$ of patients receiving liraglutide $1.2 \mathrm{mg}$ and $1.8 \mathrm{mg}$, respectively. Liraglutide $1.2 \mathrm{mg}$ and $1.8 \mathrm{mg}$ treatment resulted in reductions in fasting plasma glucose $(-40 \mathrm{mg} / \mathrm{dL}$ and $-43 \mathrm{mg} / \mathrm{dL}$, respectively) and postprandial glucose levels $(-49 \mathrm{mg} / \mathrm{dL}$ and $-47 \mathrm{mg} / \mathrm{dL}$, respectively). Patients receiving placebo experienced a mean increase in body weight of $0.6 \mathrm{~kg}$ compared with a mean weight loss of $-1.0 \mathrm{~kg}$ and $-2.0 \mathrm{~kg}$ for liraglutide 1.2 and $1.8 \mathrm{mg}$ ( $P<0.05$ versus placebo for both liraglutide doses).

\section{Liraglutide versus glargine as add-on to baseline metformin and glimepiride}

LEAD-5 aimed to compare liraglutide with insulin glargine as add-on therapy to metformin and glimepiride. ${ }^{46}$ LEAD-5 enrolled a total of 581 patients with T2DM with a mean baseline $\mathrm{HbA}_{1 \mathrm{c}}$ of $8.2 \%$. Participants received liraglutide $1.8 \mathrm{mg} /$ day, liraglutide placebo, or insulin glargine in addition to metformin $1 \mathrm{~g}$ twice daily and glimepiride (2-4 mg/day) for a duration of 26 weeks. The dose of insulin glargine was individually titrated according to a patient-driven algorithm, with a mean dose of 24 units per day reported at the end of the trial in the insulin glargine arm. Mean $\mathrm{HbA}_{1 \mathrm{c}}$ values were decreased $-1.33 \%$, $-0.24 \%$, and $-1.09 \%$ with the addition of liraglutide, placebo, and insulin glargine, respectively $(P<0.05$ for liraglutide versus placebo and insulin glargine). An $\mathrm{HbA}_{1 \mathrm{c}}$ below 6.5\% was achieved in $37.1 \%$ of patients treated with liraglutide, $10.9 \%$ of those treated with placebo $(P<0.0001$ versus liraglutide), and $23.6 \%$ of patients in the insulin glargine group $(P=0.0001$ versus liraglutide). A mean body weight reduction of $-1.81 \mathrm{~kg}$ was reported in the liraglutide group $(P<0.0001$ versus glargine; $P=0.0001$ versus placebo), with a mean weight loss of $-0.42 \mathrm{~kg}$ in the placebo group, and a $1.62 \mathrm{~kg}$ weight gain seen in the insulin glargine group.

\section{Liraglutide versus exenatide as add-on to baseline metformin and/or a sulfonylurea}

LEAD-6 was a 26-week trial in 464 patients inadequately treated with metformin and/or a sulfonylurea with a mean baseline $\mathrm{HbA}_{1 \mathrm{c}}$ of $8.2 \% .{ }^{41}$ This trial aimed to compare liraglutide $1.8 \mathrm{mg}$ /day to exenatide $10 \mu \mathrm{g}$ twice daily as add-on therapy. $\mathrm{HbA}_{1 \mathrm{c}}$ reductions of $-1.12 \%$ for liraglutide and $-0.79 \%$ for exenatide were observed $(P<0.0001)$. A target $\mathrm{HbA}_{1 \mathrm{c}}$ less than $6.5 \%$ was achieved in $35 \%$ of those treated with liraglutide versus $21 \%$ for patients receiving exenatide $(P<0.0001)$. Changes in body weight were similar in both groups with no statistical differences in weight change between the liraglutide and exenatide treatment groups. Weight reductions of $-3.2 \mathrm{~kg}$ and $-2.9 \mathrm{~kg}$ for liraglutide and exenatide were observed, respectively.

\section{Additional clinical endpoints}

Clinical studies with liraglutide have also demonstrated potential benefits of therapy on $\beta$-cell function and the cardiovascular system. One study utilized a graded glucose protocol to assess the effects of a single liraglutide dose of $7.5 \mu \mathrm{g} / \mathrm{kg}$ on insulin secretion. ${ }^{47}$ Insulin secretion increased with elevation in blood glucose in all groups, however liraglutide treatment resulted in a more pronounced insulin response which was similar to that observed in healthy control subjects. Other clinical studies have shown improvements in glucose-induced insulin secretion, $\beta$-cell sensitivity, and suppression of 
24-hour glucagon secretion following 1 week of therapy, ${ }^{37}$ and sustained $\beta$-cell sensitivity to glucose over 12 weeks of therapy. ${ }^{48}$ Regarding the effects of liraglutide treatment on cardiovascular health, statistically significant decreases in systolic blood pressure, ranging from 2 to $7.9 \mathrm{mmHg}$, have been observed in clinical trials. ${ }^{43,44,49}$ The mechanism resulting in the observed reduction in systolic blood pressure is unknown, but appears unrelated to concomitant weight loss. ${ }^{50}$ Early data additionally indicates liraglutide treatment may also decrease cardiovascular markers such as PAI-1 and BNP, but the clinical implications, either positive or detrimental, of these findings are unknown.

\section{Safety and tolerability Hypoglycemia}

Of paramount importance in any newly approved drug used to treat T2DM is the likelihood of hypoglycemia, when used as mono-, dual-, or even as part of a triple-therapy regimen. In the LEAD trials, a minor hypoglycemic event was defined as a plasma glucose concentration of $<56 \mathrm{mg} / \mathrm{dL}$ that was resolved with self-treatment, and a major hypoglycemic event was defined as a hypoglycemic event requiring third party assistance. Note that in LEAD-1, self-treatment was the sole criteria used to classify a hypoglycemic event as minor. ${ }^{42}$ As expected, trials utilizing combination sulfonylurea therapy resulted in the highest incidence of hypoglycemia. LEAD-1 involved patients on concurrent sulfonylurea therapy (glimepiride). ${ }^{42}$ In this trial, the percentage of patients experiencing minor hypoglycemia was reported as glimepiride monotherapy (placebo) 2.6\%, 0.17 events/subject-year; liraglutide $0.6 \mathrm{mg}, 5.2 \%, 0.17$ events/subject-year; liraglutide $1.2 \mathrm{mg} 9.2 \%, 0.51$ events/subject-year; liraglutide $1.8 \mathrm{mg}$, $8.1 \%, 0.47$ events/subject-year; and rosiglitazone $4.3 \%$, 0.12 events/subject-year. Table 2 provides a summary of adverse event findings from the LEAD program. Furthermore, in the $1.8 \mathrm{mg}$ liraglutide plus glimepiride cohort, one major hypoglycemic event occurred. ${ }^{42}$

In LEAD-2, the percentage of patients experiencing minor hypoglycemia was low in the placebo and liraglutide cohorts, roughly $3 \%$, while $17 \%$ of subjects receiving glimepiride reported an incidence of minor hypoglycemia. ${ }^{43}$ Major hypoglycemic events did not occur in LEAD-2. There were

Table 2 Adverse drug event rates in Liraglutide Effects and Action in Diabetes (LEAD) trials

\begin{tabular}{|c|c|c|c|c|c|c|c|c|c|}
\hline Study & Drug & $\begin{array}{l}\text { Patients } \\
\text { experiencing } \\
\text { minor } \\
\text { hypoglycemia } \\
\text { (\%) }\end{array}$ & $\begin{array}{l}\text { Major } \\
\text { hypoglycemic } \\
\text { events }(n)\end{array}$ & $\begin{array}{l}\text { Nausea } \\
\text { (\%) }\end{array}$ & $\begin{array}{l}\text { Vomiting } \\
\text { (\%) }\end{array}$ & $\begin{array}{l}\text { GI } \\
\text { events } \\
(\%)\end{array}$ & $\begin{array}{l}\text { Pancreatitis } \\
\text { (number of } \\
\text { subjects) }\end{array}$ & $\begin{array}{l}\text { Pulse } \\
\text { rate } \\
(\text { bpm) }\end{array}$ & $\begin{array}{l}\text { Liraglutide } \\
\text { antibody } \\
\text { formation } \\
\text { (\%) }\end{array}$ \\
\hline \multirow[t]{5}{*}{ LEAD- ${ }^{42}$} & Liraglutide $0.6 \mathrm{mg}$ & 5.2 & 0 & NR & NR & NR & 1 & $+2-4^{\mathrm{ab}}$ & $9-13^{a}$ \\
\hline & Liraglutide $1.2 \mathrm{mg}$ & $9.2^{c, d}$ & 0 & 10.5 & 4.4 & NR & 0 & & \\
\hline & Liraglutide $1.8 \mathrm{mg}$ & $8.1^{\mathrm{e}}$ & I & NR & NR & NR & 0 & & \\
\hline & Rosiglitazone $4 \mathrm{mg}$ & 4.3 & 0 & NR & NR & NR & 0 & +1 & NA \\
\hline & Placebo & 2.6 & 0 & 1.8 & NR & NR & 0 & -1 & NA \\
\hline \multirow[t]{5}{*}{ LEAD- $2^{43}$} & Liraglutide $0.6 \mathrm{mg}$ & $3^{\text {af }}$ & 0 & 11 & $5-7^{a}$ & 35 & 0 & $+2-3^{\mathrm{ag}}$ & $N R$ \\
\hline & Liraglutide $1.2 \mathrm{mg}$ & & & 16 & & 40 & 1 & & NR \\
\hline & Liraglutide $1.8 \mathrm{mg}$ & & & 19 & & 44 & 0 & & NR \\
\hline & Glimepiride 4 mg & 17 & 0 & NR & I & 17 & 1 & +1 & NA \\
\hline & Placebo & 3 & 0 & $N R$ & $\mathrm{I}$ & 17 & 0 & +1 & NA \\
\hline \multirow[t]{3}{*}{ LEAD-3 ${ }^{44}$} & Liraglutide $1.2 \mathrm{mg}$ & $12^{f}$ & 0 & $27.5^{f}$ & 9.3 & 49 & 1 & $+3.2^{\mathrm{h}}$ & NR \\
\hline & Liraglutide $1.8 \mathrm{mg}$ & $8^{f}$ & 0 & $29.3^{f}$ & 12.4 & 51 & 1 & +1.6 & NR \\
\hline & Glimepiride 8 mg & 24 & 0 & 8.5 & 3.6 & 26 & 0 & +0.4 & NA \\
\hline \multirow[t]{3}{*}{ LEAD- $4^{45}$} & Liraglutide $1.2 \mathrm{mg}$ & 9.0 & 0 & 29 & 7 & 45 & 0 & +2 & 4.1 \\
\hline & Liraglutide $1.8 \mathrm{mg}$ & $7.9 i$ & 0 & 40 & 17 & 56 & 0 & +3 & 6.7 \\
\hline & Placebo & 5.1 & 0 & NR & NR & 19 & 0 & -0.5 & 0 \\
\hline \multirow[t]{3}{*}{ LEAD-5 ${ }^{46}$} & Liraglutide $1.8 \mathrm{mg}$ & 27.5 & 5 & 13.9 & 6.5 & NR & 0 & +2.62 & 9.8 \\
\hline & Insulin glargine & 28.9 & 0 & 1.3 & 0.4 & NR & 0 & +0.08 & NA \\
\hline & Placebo & 16.7 & 0 & 3.5 & 3.5 & NR & 0 & +0.93 & NA \\
\hline \multirow[t]{2}{*}{ LEAD-6 ${ }^{41}$} & Liraglutide $1.8 \mathrm{mg}$ & $26^{i}$ & 0 & 25.5 & 6.0 & 45.5 & 1 & $+3.28^{k}$ & NR \\
\hline & Exenatide $10 \mu \mathrm{g}$ bid & 34 & 2 & 28.0 & 9.9 & 42.7 & 0 & +0.69 & NA \\
\hline
\end{tabular}

Notes: ${ }^{a}$ Reported composite for all liraglutide doses tested; ${ }^{b} P \leq 0.002$ versus placebo; ${ }^{c} P=0.0024$ versus comparator; ${ }^{d} P=0.048$ versus placebo; ${ }^{e} P=0.0065$ versus comparator; ${ }^{f} P<0.00$ I versus comparator; ${ }^{g} P<0.03$ for $0.6 \mathrm{mg}$ and $1.2 \mathrm{mg}$ liraglutide groups versus comparator; ${ }^{\mathrm{h}} P=0.0027$ versus comparator; $i \mathrm{P}=0.004$ versus $p$ lacebo; $\mathrm{j} P=0.013 \mathrm{I}$ versus comparator; ${ }^{\mathrm{N}} \mathrm{P}=0.0012$ versus comparator.

Abbreviations: bid, twice daily; bpm, beats per minute; Gl, gastrointestinal; NA, not applicable; NR, not reported. 
a low percentage of patients reporting minor hypoglycemic events in LEAD-3, with $8 \%$ of the subjects in the liraglutide $1.8 \mathrm{mg}$ group ( 0.25 events per year) and $12 \%$ of subjects in the $1.2 \mathrm{mg}$ group experiencing minor hypoglycemic events ( 0.3 events per year) ${ }^{44}$ Twenty-four percent of subjects in the glimepiride group reported minor hypoglycemic events while no major hypoglycemic events occurred in any of the groups in this 52-week trial.

Minor hypoglycemia was reported in LEAD-4 at rates of $9 \%, 7.9 \%$, and $5.1 \%$ of subjects in the $1.2 \mathrm{mg}$ liraglutide, $1.8 \mathrm{mg}$ liraglutide, and placebo groups, respectively. ${ }^{45}$ No major hypoglycemic events were reported. In LEAD-5, $27.4 \%$ of the patients receiving liraglutide experienced at least 1 episode of minor hypoglycemia (1.2 events/subject/year), while $28.9 \%$ (1.3 events/subject/year) and $16.7 \%$ (1.0 events/subject/year) experienced minor hypoglycemia in the insulin glargine and placebo groups, respectively. ${ }^{46}$ In the liraglutide group, 5 subjects reported a major hypoglycemic episode, with no major hypoglycemic events reported in the other two cohorts.

In the open-label 26-week trial known as LEAD-6, minor hypoglycemia occurred in $26 \%$ and $34 \%$ of the liraglutide and exenatide groups, respectively; correlating to event rates of 1.9 (liraglutide) and 2.6 (exenatide) events per subject per year. ${ }^{41}$ Two cases of major hypoglycemia occurred in subjects exposed to exenatide and a sulfonylurea.

\section{Gastrointestinal adverse events}

In the LEAD-1 trial, incomplete data were provided for all arms of the study in regard to gastrointestinal (GI) side effects. ${ }^{42}$ The most complete data reveal that nausea was highest in the liraglutide $1.2 \mathrm{mg}$ cohort (10.5\%) compared with an event rate of $1.8 \%$ in the placebo group. Additionally, $4.4 \%$ and $7.9 \%$ of those in the $1.2 \mathrm{mg}$ liraglutide group experienced vomiting and diarrhea, respectively.

The LEAD-2 trial involved subjects on a wide range of oral therapies that included metformin, sulfonylureas, repaglinide, or some combination of these listed medications. ${ }^{43}$ GI adverse events were pronounced in this trial, with $35 \%$ of the subjects in the $0.6 \mathrm{mg}$ liraglutide group experiencing GI side effects, including nausea, vomiting, and diarrhea, with $40 \%$ and $44 \%$ experiencing these GI-related adverse events in the $1.2 \mathrm{mg}$ and $1.8 \mathrm{mg}$ groups, respectively. This is in comparison with $17 \%$ of the placebo-treated group reporting GI-associated adverse events. Five percent (36 subjects) of those receiving any dose of liraglutide withdrew from the study due to GI-related adverse events.

In LEAD-3, nausea occurred in $27.5 \%, 29.3 \%$, and $8.5 \%$ of participants in the $1.2 \mathrm{mg}$ liraglutide, $1.8 \mathrm{mg}$ liraglutide, and glimepiride groups, respectively. ${ }^{44}$ Vomiting occurred in $3.6 \%$ of subjects receiving glimepiride, while this side effect occurred in $9.3 \%$ and $12.4 \%$ of those receiving $1.2 \mathrm{mg}$ and $1.8 \mathrm{mg}$ of liraglutide, respectively. Diarrhea was reported by $15.5 \%, 18.7 \%$, and $8.9 \%$ of participants in the $1.2 \mathrm{mg}$ liraglutide, $1.8 \mathrm{mg}$ liraglutide, and glimepiride groups, respectively. A total of 6 participants (1.2\%) receiving liraglutide withdrew from the study due to vomiting, while a total of 17 participants (3.4\%) receiving liraglutide withdrew for any GI-related complaint. In the 26-week study known as LEAD-4, 29\% of subjects receiving $1.2 \mathrm{mg}$ liraglutide experienced nausea while $40 \%$ of subjects in the $1.8 \mathrm{mg}$ liraglutide group reported this adverse event. ${ }^{45}$ Vomiting was reported by $7 \%$ and $17 \%$ of subjects in the $1.2 \mathrm{mg}$ and $1.8 \mathrm{mg}$ liraglutide groups, respectively. When all GI adverse events were grouped (nausea, vomiting, diarrhea), 19\% of those receiving placebo and $45 \%$ and $56 \%$ of those receiving $1.2 \mathrm{mg}$ and $1.8 \mathrm{mg}$ of liraglutide, respectively, reported GI-related complaints. GI adverse events contributed to 5 withdrawals (3\% of participants) in the liraglutide $1.2 \mathrm{mg}$ group and 19 (10.7\% of participants) in the liraglutide $1.8 \mathrm{mg}$ group.

Nausea occurred in $13.9 \%$ of those receiving liraglutide, $3.5 \%$ in placebo arm, and $1.3 \%$ of participants in the insulin glargine group in LEAD-5. ${ }^{46}$ In this trial, diarrhea was reported in $10 \%, 5.3 \%$, and $1.3 \%$ in the liraglutide, placebo, and insulin glargine groups, respectively. Vomiting occurred in $6.5 \%, 3.5 \%$, and $0.4 \%$ in the liraglutide, placebo, and insulin glargine groups, respectively. Dyspepsia was also reported in this trial, with $6.5 \%, 0.9 \%$, and $1.7 \%$ of subjects in the liraglutide, placebo, and insulin glargine groups, respectively, experiencing this GI-related adverse event. Four subjects in LEAD-5 receiving liraglutide withdrew from the study due to GI-related adverse events. LEAD-6 reported similar rates of GI-related adverse events between the liraglutide and exenatide groups. ${ }^{41}$ Overall, GI adverse events occurred in $45.5 \%$ and $42.7 \%$ of liraglutide- and exenatide-treated subjects, respectively, with nausea being the most frequently reported event. Nausea tended to resolve over time with both therapies, however, with $2.5 \%$ of the liraglutide group reporting nausea at week 26 compared with $15.8 \%$ of those receiving exenatide therapy. ${ }^{41}$ Vomiting occurred in $6.0 \%$ and $9.9 \%$ of the liraglutide and exenatide groups, respectively.

From the above data it can be seen that nausea is a frequent adverse event in subjects receiving liraglutide. However, nausea was most pronounced in the first 4 weeks of therapy, with symptoms generally dissipating over the remainder of the study period in all trials. 


\section{Pulse rate}

The effects of liraglutide on pulse rate ranged from an increase of $2-4$ beats per minute (bpm) in subjects receiving liraglutide $(P \leq 0.002$ versus placebo; $P<0.01$ versus rosiglitazone), with pulse increasing by a mean $1 \mathrm{bpm}$ in subjects receiving rosiglitazone, and pulse decreasing by a mean $1 \mathrm{bpm}$ in the placebo group. ${ }^{42}$ In the LEAD-2 trial, pulse rates increased by a mean $2-3 \mathrm{bpm}$ in those receiving liraglutide, compared with a $1 \mathrm{bpm}$ increase in the glimepiride and placebo groups. ${ }^{43}$ The mean pulse rate in LEAD-3 increased by $0.4,3.2$, and $1.6 \mathrm{bpm}$ for the glimepiride group and the $1.2 \mathrm{mg}$ and $1.8 \mathrm{mg}$ liraglutide groups, respectively. ${ }^{44}$ Pulse rate increased by $2 \mathrm{bpm}$ in subjects receiving liraglutide in LEAD-4, with mean pulse rates increasing by $3 \mathrm{bpm}$ in those receiving liraglutide $1.8 \mathrm{mg} .{ }^{45}$ Pulse rate increased by a mean of $2.62 \mathrm{bpm}$ in those subjects receiving liraglutide in LEAD-5, while increases of $0.08 \mathrm{bpm}$ and $0.93 \mathrm{bpm}$ were experienced by those in the insulin glargine and placebo groups, respectively. ${ }^{46}$ In LEAD-6, heart rates increased by a mean of $3.28 \mathrm{bpm}$ in the liraglutide group compared with $0.69 \mathrm{bpm}$ in the exenatide group. ${ }^{41}$

\section{Pancreatitis}

Pancreatitis has been reported in clinical trials with liraglutide. In LEAD-1, one subject receiving liraglutide $0.6 \mathrm{mg}$ developed pancreatitis but successfully completed the trial. ${ }^{42}$ Two subjects withdrew from the LEAD-2 study after developing pancreatitis, 1 receiving liraglutide and 1 receiving glimepiride. ${ }^{43} 1$ participant in each of the liraglutide groups in LEAD-3 developed pancreatitis, with one completing the trial. ${ }^{44}$ No cases of pancreatitis were reported in the 26-week LEAD-4 or LEAD-5 trials. ${ }^{45,46}$ Likewise, no cases of acute pancreatitis were reported in LEAD-6; however 1 case of mild pancreatitis occurred in a subject receiving liraglutide who subsequently completed the 26 -week trial. ${ }^{41}$

\section{Anti-liraglutide antibodies}

In LEAD-1, 9\%-13\% of subjects exposed to liraglutide during the 26-week trial developed anti-liraglutide antibodies. ${ }^{42}$ The LEAD-2 and LEAD-3 trials did not measure the development of liraglutide antibody formation. In LEAD-4, 6 subjects in the liraglutide $1.2 \mathrm{mg}$ group and 9 subjects in the liraglutide $1.8 \mathrm{mg}$ group developed antibodies. ${ }^{45} \mathrm{In}$ LEAD-5, 23 subjects $(9.8 \%)$ of subjects developed antiliraglutide antibodies during the 26 -week study. ${ }^{46}$ Because the LEAD-6 trial involves an extension phase where subjects may continue to take liraglutide, antibody determination will be completed once the trial is complete and after an appropriate washout period; these data are not currently available. ${ }^{41}$ While the clinical impact of anti-liraglutide antibodies is unknown at this time, further study of this phenomenon is warranted.

\section{Additional safety considerations}

Study withdrawal rates due to adverse drug events and event rates for serious adverse events reported in the six LEAD trials are summarized in Table 3. Interestingly, injection-related adverse events such as injection site rash, were not reported in any of the LEAD trials. In addition to the adverse drug events discussed above, peripheral edema was reported in the LEAD-4 trial, likely due to participants also receiving concomitant rosiglitazone. ${ }^{45}$ In this trial, peripheral edema occurred in $5.1 \%, 1.7 \%$, and $8.0 \%$ of the subjects in the $1.2 \mathrm{mg}$ liraglutide, $1.8 \mathrm{mg}$ liraglutide, and placebo groups, respectively. The LEAD studies indicate liraglutide to be generally safe, however the development of rare adverse events is of concern until patients at heightened risk for developing events such as pancreatitis can be identified. The safety and tolerability of liraglutide can only truly be assessed with robust Phase IV post-marketing data involving long-term treatment with this novel therapy.

An additional theoretical concern raised in the liraglutide prescribing information is a warning regarding the observation of dose-dependent and treatment-duration-dependent thyroid C-cell tumors witnessed at clinically relevant exposures in rats and mice. ${ }^{13}$ During clinical trials with liraglutide, calcitonin, a biomarker for the detection of medullary thyroid cancer, was monitored routinely. ${ }^{51}$ During the LEAD program, increases in calcitonin levels did occur in a slightly higher percentage of patients treated with liraglutide when compared with controls, however, calcitonin levels remained within normal ranges. ${ }^{51}$ Ultimately, while it is unknown if this is clinically relevant in humans, liraglutide is contraindicated in patients with a personal or family history of medullary thyroid carcinoma, and in patients with multiple endocrine neoplasia syndrome type $1 .{ }^{13}$ The FDA has requested the establishment of a cancer registry to monitor the annual incidence of medullary thyroid cancer over the next 15 years. ${ }^{51}$

\section{Administration}

Liraglutide was approved in July of 2009 by the European Commission for marketing consideration to all 27 European Union members. ${ }^{52}$ Liraglutide is administered as a 
Table 3 Clinical study withdrawal and serious adverse event rates in Liraglutide Effects and Action in Diabetes (LEAD) trials

\begin{tabular}{|c|c|c|c|}
\hline Study & Drug & Discontinuation due to $\mathrm{ADE}^{\mathrm{a}}$ (\%) & Serious adverse events \\
\hline \multirow[t]{5}{*}{ LEAD-I 42} & Liraglutide $0.6 \mathrm{mg}$ & 20 & $3 \%$ \\
\hline & Liraglutide $1.2 \mathrm{mg}$ & 34 & $4 \%$ \\
\hline & Liraglutide 1.8 mg & 43 & $5 \%$ \\
\hline & Rosiglitazone $4 \mathrm{mg}$ & 19 & $3 \%$ \\
\hline & Placebo & 19 & $3 \%$ \\
\hline \multirow[t]{5}{*}{ LEAD- $2^{43}$} & Liraglutide $0.6 \mathrm{mg}$ & 32 & NR \\
\hline & Liraglutide $1.2 \mathrm{mg}$ & 52 & NR \\
\hline & Liraglutide $1.8 \mathrm{mg}$ & 57 & NR \\
\hline & Glimepiride 4 mg & 23.5 & NR \\
\hline & Placebo & 4 & NR \\
\hline \multirow[t]{3}{*}{ LEAD-3 ${ }^{44}$} & Liraglutide $1.2 \mathrm{mg}$ & 28 & 16 subjects/ 18 events \\
\hline & Liraglutide $1.8 \mathrm{mg}$ & 24 & 8 subjects $/ 9$ events \\
\hline & Glimepiride 8 mg & 16 & 13 subjects/ 17 events \\
\hline \multirow[t]{3}{*}{ LEAD $-4^{45}$} & Liraglutide $1.2 \mathrm{mg}$ & 44 & 8 subjects $/ 8$ events \\
\hline & Liraglutide $1.8 \mathrm{mg}$ & 60 & 7 subjects/ 10 events \\
\hline & Placebo & 10.7 & 12 subjects/ 13 events \\
\hline \multirow[t]{3}{*}{ LEAD $-5^{46}$} & Liraglutide $1.8 \mathrm{mg}$ & 48 & NR \\
\hline & Insulin glargine & 38.5 & $N R$ \\
\hline & Placebo & 5.5 & $N R$ \\
\hline \multirow[t]{2}{*}{ LEAD-6 ${ }^{41}$} & Liraglutide $1.8 \mathrm{mg}$ & 70 & $5.1 \%$ \\
\hline & Exenatide $10 \mu \mathrm{g}$ bid & 69 & $2.6 \%$ \\
\hline
\end{tabular}

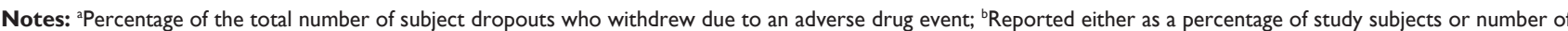
subjects and number of events.

Abbreviations: ADE, adverse drug event; NR, not reported.

subcutaneous injection for once-daily treatment of T2DM, as an adjunct therapy in combination with metformin, a sulfonylurea, or metformin plus a sulfonylurea or thiazolidinedione..$^{53}$ The approved dosing for use in Europe is an initial dose of $0.6 \mathrm{mg}$ daily for one week, with a recommended titration to $1.2 \mathrm{mg}$ daily after the first week. The maximum recommended daily dose is $1.8 \mathrm{mg}$ for patients who are not well controlled and who can tolerate the higher titrated dose, although doses as high as $2 \mathrm{mg}$ daily have been used in clinical trials.$^{54}$ The LEAD studies found that titrating liraglutide by $0.6 \mathrm{mg}$ weekly improved the tolerability and reduced the occurrence of GI adverse events. ${ }^{43}$ Injection site reactions are another concern, and should be monitored for during liraglutide initiation. ${ }^{13}$ Liraglutide received FDA approval for use in the US in January 2010 as an adjunct to diet and exercise to improve glycemic control in adults with T2DM. ${ }^{13}$ Similar to Europe, in the US liraglutide is recommended at a starting dose of $0.6 \mathrm{mg}$ daily for the first week, followed by an upward titration to $1.2 \mathrm{mg}$ daily. ${ }^{13}$ For those patients not achieving the desired glycemic control at the $1.2 \mathrm{mg}$ dose, the dose can likewise be increased to $1.8 \mathrm{mg}$. As per the prescribing information, it is also recommended that a reduction in the dose of pre-existing insulin secretagogue medications be considered when initiating liraglutide to minimize the risk of treatment-emergent hypoglycemia. ${ }^{13}$ Liraglutide is available commercially in the US as a simple pen capable of administering $0.6,1.2$, and $1.8 \mathrm{mg}$ doses.

\section{Patient-specific considerations}

A common problem among T2DM patients is the issue of weight management. Elevated body weight or obesity, and an increased risk of cardiovascular-related complications often increase the medical burden and medication load of the patient. ${ }^{55}$ The patient is often prescribed a medication regimen that is counterproductive to weight loss, which decreases treatment satisfaction due to resulting weight gain. Newer GLP-1 agonists, such as exenatide and liraglutide, are associated with weight reduction in healthy and diabetic subjects. ${ }^{41}$ A comparative trial of exenatide and liraglutide in T2DM subjects concluded that both exenatide and liraglutide were associated with a significant reduction in body weight when compared with baseline $(-2.87 \mathrm{~kg}$ and $-3.24 \mathrm{~kg}$, respectively). ${ }^{41}$ In the LEAD-3 trial, weight loss was reported in both the $1.2 \mathrm{mg}$ and $1.8 \mathrm{mg}$ liraglutide monotherapy groups, with an average loss of $-2 \mathrm{~kg}$ and $-2.5 \mathrm{~kg}$, respectively $(P<0.0001) .{ }^{44}$ Reported weight loss occurred during the first 16 weeks, but was sustained throughout the remaining 36 weeks of treatment. After completion of a second 52-week open-label study period, weight reductions of $-2.1 \mathrm{~kg}$ and $-2.7 \mathrm{~kg}$ for both the $1.2 \mathrm{mg}$ and $1.8 \mathrm{mg}$ liraglutide 
study groups, respectively, were significant when compared with those receiving glimepiride $(P<0.0001) .{ }^{44}$ In all LEAD studies completed, liraglutide $1.8 \mathrm{mg}$ daily was associated with reported weight reductions of $-0.2 \mathrm{~kg}$ to $-3.24 \mathrm{~kg}$ over a period of at least 6 months. ${ }^{41-46}$ Of additional interest, an analysis of patients from LEAD-1 and LEAD-2 reported that weight reductions in patients receiving liraglutide were primarily due to reductions in fat mass rather than lean tissue mass. ${ }^{56}$ Finally, a trial enrolling healthy, nondiabetic patients with a mean baseline BMI of $30-40 \mathrm{~kg} / \mathrm{m}^{2}$ compared the weight effects of liraglutide at doses of $1.2,1.8,2.4$, and $3 \mathrm{mg}$ daily, versus orlistat $120 \mathrm{mg}$ three times daily or placebo. ${ }^{57}$ Weight loss in liraglutide subjects was $-4.8 \mathrm{~kg}$ in the $1.2 \mathrm{mg}$ group $(P=0.003),-5.5 \mathrm{~kg}$ in the $1.8 \mathrm{mg}$ group $(P<0.0001)$, $-6.3 \mathrm{~kg}$ in the $2.4 \mathrm{mg}$ group $(P<0.0001)$, and $-7.2 \mathrm{~kg}$ in the $3.0 \mathrm{mg}$ group $(P<0.0001)$ when compared with baseline.

Quality of life was another indicator of treatment outcome that was evaluated in select clinical trials. Astrup et al found that mean physical function improved in the liraglutide $3.0 \mathrm{mg}$ group by a score of $6.8(P=0.001)$ when compared with placebo, and by 6.0 when compared with the orlistat treatment group $(P=0.006) .{ }^{57}$ Mean self-esteem also increased in the $3.0 \mathrm{mg}$ daily group by a score of 9.6 when compared with placebo $(P=0.0001)$, and by 6.2 when compared with the orlistat treatment group $(P=0.04)$. Patient-reported outcomes were also investigated in the LEAD-3 trial. Compared with glimepiride, the liraglutide $1.8 \mathrm{mg}$ cohort reported a mean decrease in BMI that was associated with improvements in both weight image and weight concern $(P<0.0001) .{ }^{44}$ Decreases in weight concern were associated with increases in overall quality of life, general perception of their health (both $P<0.0001)$, and mental/emotional health $(P=0.002)$. Finally, in LEAD-6, subjects were assessed for treatment satisfaction using the Diabetes Treatment Satisfaction Questionnaire. ${ }^{41}$ Overall treatment satisfaction was reported to be significantly higher in the liraglutide group when compared with the exenatide group $(P=0.0004)$.

Future studies regarding adherence and continued impact on patient quality of life would be of value to the clinical community, with the unique kinetic parameters of liraglutide, as well as its positive impact on weight, lending merit to liraglutide as a viable option for the treatment of T2DM.

\section{Discussion}

The pharmacokinetic profile of liraglutide is amenable to once-daily dosing, thus creating a potential advantage when compared with twice-daily exenatide. Drug regimen simplicity is an important clinical consideration, particularly in patients receiving multiple medications for the treatment of T2DM and related comorbidities. Patients often present with resistance to the initiation of an injectable agent, however the potential for weight loss with the incretin mimetics and incretin analogs can be a motivator for some patients. The most recent consensus algorithm released by the ADA and the European Association for the Study of Diabetes lists GLP-1 analogs as a treatment option for consideration as a Tier 2 agent, or "less well-validated therapy", in T2DM patients. ${ }^{9}$ The consensus guideline recommends consideration of GLP-1 agonist therapy in selected clinical situations. One situation in which GLP-1 agonist therapy could be considered is if weight loss is a major consideration and the patient's $\mathrm{HbA}_{1 \mathrm{c}}$ level is close to target $(<8.0 \%) .{ }^{9}$ The guideline warns, however, that GLP-1 agonist therapy is not indicated for all patients and should be used with caution in those with a history of significant GI disease, such as a diagnosis of gastroparesis, due to a possible exacerbation of such conditions with incretin mimetic therapy. ${ }^{9}$ Because postprandial hyperglycemia affects $\mathrm{HbA}_{1 \mathrm{c}}$ to a greater degree than fasting hyperglycemia, the closer a patient is to their $\mathrm{HbA}_{1 \mathrm{c}}$ goal, GLP-1 agonists, such as liraglutide, provide a viable treatment option to target postprandial glucose excursions due to their glucose-dependent effects on insulin secretion.

\section{Conclusion}

Clinical trial data from large, controlled studies demonstrate the efficacy and safety of liraglutide in terms of $\mathrm{HbA}_{1 \mathrm{c}}$ reduction, beneficial effects on body weight, and a low risk for hypoglycemic events when used as monotherapy. Liraglutide is relatively well tolerated, with dose-dependent nausea, vomiting, and diarrhea being the most commonly reported adverse events observed in clinical trials. Clinical trial data in humans indicate that liraglutide may have a role in the treatment of T2DM patients as monotherapy early in the disease process, as well as in combination with metformin, glimepiride, and rosiglitazone in patients inadequately controlled on oral antidiabetic drugs. Comparative data with exenatide twicedaily indicate a potential therapeutic advantage for liraglutide in terms of ease of use, with similar improvements in $\mathrm{HbA}_{1 \mathrm{c}}$ and body weight seen when comparing these two agents. Data are currently not available comparing liraglutide with once-weekly exenatide currently under Phase III study, however. Questions do remain regarding the safety of this agent in terms of risk of pancreatitis and medullary thyroid carcinoma. While the risk of such events is assumed to be small, vigorous postmarketing surveillance and reporting is 
warranted to identify patients that may be at increased risk for experiencing such events.

\section{Disclosure}

The authors report no conflicts of interest in relation to the content or production of this article.

\section{References}

1. World Health Organization. Diabetes Fact Sheet. Available from: http:// www.who.int/mediacentre/factsheets/fs312/en/index.html Accessed Dec 29, 2009.

2. Centers for Disease Control and Prevention. National Diabetes Fact Sheet: General Information and National Estimates on Diabetes in the United States, 2007. Atlanta, GA: US Department of Health and Human Services, Centers for Disease Control and Prevention; 2008.

3. Ong KL, Cheung BM, Wong LY, et al. Prevalence, treatment and control of diagnosed diabetes in the U.S. National Health and Nutrition Examination Survey 1999-2004. Ann Epidemiol. 2008;18:222-229.

4. Resnick HE, Foster GL, Bardsley J, et al. Achievement of American Diabetes Association clinical practice recommendations among US adults with diabetes, 1999-2002: The National Health and Nutrition Examination Survey. Diabetes Care. 2006;29:531-537.

5. Turner, RC, Cull CA, Frighi V, et al. UK Prospective Diabetes Study (UKPDS) Group. Glycemic control with diet, sulfonylurea, metformin, or insulin in patients with type 1 diabetes mellitus: Progressive requirement for multiple therapies (UKPDS 49). JAMA. 1999;281:2005-2012.

6. Holman RR, Paul SK, Bethel MA, et al. 10-year follow-up of intensive glucose control in type 1 diabetes. $N$ Engl $J$ Med. 2008;359: 1577-1589.

7. UK Prospective Diabetes Study Group. UK Prospective Diabetes Study 16. Overview of 6 years' therapy of type I diabetes: A progressive disease. Diabetes. 1995;44:1249-1258.

8. Rodbard HW, Jellinger PS, Davidson JA, et al. Statement by an American Association of Clinical Endocrinologists/American College of Endocrinology consensus panel on type 1 diabetes mellitus: An algorithm for glycemic control. Endocr Pract. 2009;15(6):540-559.

9. Nathan DM, Buse JB, Davidson MB, et al. Medical management of hyperglycemia in type 1 diabetes: A consensus algorithm for the initiation and adjustment of therapy. Diabetes Care. 2009;32:193-203.

10. Byetta ${ }^{\circledR}$ (Package insert). San Diego, CA: Amylin Pharmaceuticals, Inc.; 2009.

11. Drucker DJ. The biology of incretin hormones. Cell Metab. 2006;3: $153-165$.

12. Farilla L, Bulotta A, Hirshberg B, et al. Glucagon-like peptide 1 inhibits cell apoptosis and improves glucose responsiveness of freshly isolated human islets. Endocrinology. 2003;144:5149-5158.

13. Victoza ${ }^{\circledR}$ (Package insert). Princeton, NJ: Novo Nordisk Inc.; 2010.

14. Elrick H, Stimmler L, Hlad CJ, et al. Plasma insulin response to oral and intravenous glucose administration. J Clin Endocrinol Metab. 1964; 24:1076-1082.

15. Drucker DJ. Enhancing incretin action for the treatment of type 1 diabetes. Diabetes Care. 2003;26:2929-2940.

16. Nauck MA, Homberger E, Siegel EG, et al. Incretin effects of increasing glucose loads in man calculated from venous insulin and C-peptide responses. J Clin Endocrinol Metab. 1986;63:492-498.

17. Nauck M, Stockmann F, Ebert R, et al. Reduced incretin effect in type 1 (non-insulin-dependent) diabetes. Diabetologia. 1986;29:46-52.

18. Orskov C, Wettergren A, Holst JJ. Secretion of the incretin hormones glucagon-like peptide- 1 and gastric inhibitory polypeptide correlates with insulin secretion in normal man throughout the day. Scand J Gastroenterol. 1996;31:665-670.

19. McKennon SA, Campbell RK. The physiology of incretin hormones and the basis for DPP-4 inhibitors. Diabetes Educ. 2007;33:55-66.
20. Vilsboll T, Holst JJ. Incretins, insulin secretion and type 1 diabetes mellitus. Diabetologia. 2004;47:357-366.

21. Vilsboll T, Krarup T, Deacon CF, et al. Reduced postprandial concentrations of intact biologically active glucagon-like peptide 1 in type 1 diabetic patients. Diabetes. 2001;50:609-613.

22. Rachman J, Barrow BA, Levy JC, et al. Near-normalisation of diurnal glucose concentrations by continuous administration of glucagon-like peptide-1 (GLP-1) in subjects with NIDDM. Diabetologia. 1997;40: 205-211.

23. Kjems LL, Holst JJ, Volund A, et al. The influence of GLP-1 on glucosestimulated insulin secretion: Effects on $\beta$-cell sensitivity in type 1 and nondiabetic subjects. Diabetes. 2003;52:380-386.

24. Hojberg PV, Zander M, Vilsboll T, et al. Near normalization of blood glucose improves the potentiating effect of GLP-1 on glucose-induced insulin secretion in patients with type 1 diabetes. Diabetologia. 2008;51:63-40.

25. Nauck MA, Heimesaat MM, Orskov C, Holst JJ, Ebert R, Creutzfeldt W. Preserved incretin activity of glucagon-like peptide 1 [7-36 amide] but not of synthetic human gastric inhibitory polypeptide in patients with type 1 diabetes mellitus. $J$ Clin Ivest. 1993;91:301-307.

26. Orskov C, Holst JJ, Nielsen OV. Effect of truncated glucagon-like peptide-1 [proglucagon-(78-107) amide] on endocrine secretion from pig pancreas, antrum, and nonantral stomach. Endocrinology. 1988;123:2009-2013.

27. Willms B, Werner J, Holst JJ, et al. Gastric emptying, glucose responses, and insulin secretion after a liquid test meal: Effects of exogenous glucagon-like peptide-1 (GLP-1)-(7-36) amide in type 1 (noninsulin-dependent) diabetic patients. J Clin Endocrinol Metab. 1996;81:327-332.

28. Nauck MA, Niedereichholz U, Ettler R, et al. Glucagon-like peptide 1 inhibition of gastric emptying outweighs its insulinotropic effects in healthy humans. Am J Physiol. 1997;273:E981-E988.

29. Flint A, Raben A, Astrup A, et al. Glucagon-like peptide 1 promotes satiety and suppresses energy intake in humans. $J$ Clin Invest. 1998;101:515-520.

30. Deacon CF, Nauck MA, Toft-Nielsen M, et al. Both subcutaneously and intravenously administered glucagon-like peptide I are rapidly degraded from the $\mathrm{NH}_{2}$-terminus in type I diabetic patients and in healthy subjects. Diabetes. 1995;44:1126-1131.

31. Knudsen LB, Nielsen PF, Huusfeldt PO, et al. Potent derivatives of glucagon-like peptide-1 with pharmacokinetic properties suitable for once daily administration. J Med Chem. 2000;43:1664-1669.

32. Gonzalez C, Beruto V, Keller G, et al. Investigational treatments for type 1 diabetes mellitus: Exenatide and liraglutide. Expert Opin Investig Drugs. 2006;15:887-895.

33. Steensgaard D, Thomsen J, Olsen H, et al. The molecular basis for the delayed absorption of the once-daily human GLP-1 analog, liraglutide. Diabetes. 2008;57:A164.

34. Agerso H, Jensen L, Elbrond B, et al. The pharmacokinetics, pharmacodynamics, safety and tolerability of NN2211, a new long-acting GLP-1 derivative, in healthy men. Diabetologia. 2002;45:195-202.

35. Elbrond B, Jakobsen G, Larsen S, et al. Pharmacokinetics, pharmacodynamics, safety, and tolerability of a single-dose of NN2211, a longacting glucagon-like peptide-1 derivative, in healthy male subjects. Diabetes Care. 2002;25:1398-1404.

36. Juhl C, Hollingdal M, Sturis J, et al. Bedtime administration of NN2211, a long-acting GLP-1 derivative, substantially reduces fasting and postprandial glycemia in type 1 diabetes. Diabetes. 2002;51: 424-429.

37. Degn K, Juhl C, Sturis J, et al. One week's treatment with the longacting glucagon-like peptide 1 derivative liraglutide (NN2211) markedly improves 24-h glycemia and alpha- and beta-cell function and reduces endogenous glucose release in patients with type 1 diabetes. Diabetes. 2004;53(5):1187-1194.

38. Jacobsen L, Hindsberger C, Robson, R, et al. Effect of renal impairment on the pharmacokinetics of the GLP-1 analog liraglutide. $\mathrm{Br} J$ Clin Pharmacol. 2009;68(6):898-905. 
39. McGill J. Insights from the Liraglutide Clinical Development Program - the Liraglutide Effect and Action in Diabetes (LEAD) studies. Postgrad Med. 2009;121(3):16-25.

40. Flint A, Nazzal K, Jagielski P, et al. Influence of hepatic impairment on pharmacokinetics of the long-acting human GLP-1 analog liraglutide. Diabetes. 2007;56:A145.

41. Buse JB, Rosenstock J, Sesti G, et al; for the LEAD-6 Study Group. Liraglutide once a day versus exenatide twice a day for type 1 diabetes: A 26-week randomised, parallel-group, multinational, open-label trial (LEAD-6) Lancet. 2009;374:39-47.

42. Marre M, Shaw J, Brandle M, et al; for the LEAD-1 SU Study Group. Liraglutide, a once-daily human GLP-1 analog, added to a sulphonylurea over 26 weeks produces greater improvements in glycaemic and weight control compared with adding rosiglitazone or placebo in subjects with type 1 diabetes (LEAD-1 SU) Diabet Med. 2009; 26:268-278

43. Nauck M, Frid A, Hermansen K, et al; for LEAD-2 Metformin Study Group. Efficacy and safety comparison of liraglutide, glimepiride, and placebo, all in combination with metformin in type 1 diabetes mellitus (LEAD-2 Met). Diabetes Care. 2009;32:84-90.

44. Garber A, Henry R, Ratner R; for the LEAD-3 (Mono) Study Group. Liraglutide versus glimepiride monotherapy for type 1 diabetes (LEAD-3 Mono): A randomized, 52-week, phase III, double-blind, parallel-treatment trial. Lancet. 2009;373:473-481.

45. Zinman B, Gerich J, Buse JB, et al; for the LEAD-4 Study Investigators. Efficacy and safety of the human glucagon-like peptide-1 analog liraglutide in combination with metformin and thiazolidinedione in patients with type 1 diabetes mellitus (LEAD-4 Met +TZD). Diabetes Care. 2009;52:2046-2055.

46. Russell-Jones D, Vaag A, Schmitz O, et al. Liraglutide vs insulin glargine and placebo in combination with metformin and sulphonylurea therapy in type 1 diabetes mellitus: A randomized controlled trial (LEAD-5 met + SU). Diabetologia. 2009;52:2046-2055.

47. Chang AM, Jakobsen G, Sturis J, et al. The GLP-1 derivative NN2211 restores $\beta$-cell sensitivity to glucose in type 1 diabetic patients after a single dose. Diabetes. 2003;52:1786-1791.
48. Madsbad S, Schmitz O, Ranstam J, Jakobsen G, Matthews DR. Improved glycemic control with no weight increase in patients with type 1 diabetes after once-daily treatment with the long-acting glucagon-like peptide 1 analog liraglutide (NN2211): A 12-week, double-blind, randomized, controlled trial. Diabetes Care. 2004;27:1335-1342.

49. Vilsboll T, Zdravkovic M, Le-Thi T, et al. Liraglutide, a long-acting human glucagon-like peptide-1 analog, given as monotherapy significantly improves glycemic control and lowers body weight without risk of hypoglycemia in patients with type 1 diabetes. Diabetes Care. 2007;30(6):1608-1610.

50. Russell-Jones D. Molecular, pharmacological and clinical aspects of liraglutide, a once-daily human GLP-1 analog. Mol Cell Endocrinol. 2009;297:137-140.

51. Parks M, Rosebraugh C. Weighing risks and benefits of liraglutide The FDA's review of a new antidiabetic therapy. $N$ Engl J Med. 362;9: 774-777.

52. NovoNordisk. Liraglutide $\left(\right.$ Victoza $\left.^{\circledR}\right)$ Press Release Available from URL: http://www.novonordisk.com/include/asp/exe_news_attachment. pdf?sAttachmentGUID=62e55769-34f2-4022-b820-7ca1cd5bffaf Accessed Jan 6, 2010

53. European Medicines Agency. Liraglutide (Victoza $\left.{ }^{\circledR}\right)$ : Summary of Product Characteristics. Available from URL: http://www.ema.europa.eu/humandocs/PDFs/EPAR/victoza/H-1026-PI-en.pdf Accessed Jan 6, 2010.

54. Nauck MA, Hompesch M, Filipczak R, et al. Five weeks of treatment with the GLP-1 analog liraglutide improves glycaemic control and lowers body weight in subjects with type 1 diabetes. Exp Clin Endocrinol Diabetes. 2006;114:417-423.

55. American Diabetes Association. Standards of medical care in diabetes: 2009. Diabetes Care. 2009;32 Suppl 1:S13-S61.

56. Jendle J, Nauck MA, Matthews DR, et al. Weight loss with liraglutide, a once-daily human glucagon-like peptide- 1 analog for type 1 diabetes treatment as monotherapy or added to metformin, is primarily as a result of a reduction in fat tissue. Diabetes Obes Metab. 2009;11:1163-1172.

57. Astrup A, Rossner S, Van Gaal L, et al. Effects of liraglutide in the treatment of obesity: A randomized, double-blind, placebo-controlled study. Lancet. 2009;374:1606-1616.

\section{Publish your work in this journal}

Diabetes, Metabolic Syndrome and Obesity: Targets and Therapy is an international, peer-reviewed open-access journal committed to the rapid publication of the latest laboratory and clinical findings in the fields of diabetes, metabolic syndrome and obesity research. Original research, review, case reports, hypothesis formation, expert opinion and commentaries are all considered for publication. The manuscript management system is completely online and includes a very quick and fair peer-review system, which is all easy to use. Visit http://www.dovepress.com/testimonials.php to read real quotes from published authors. 